\title{
La primera crónica de Miguel Hernández: el nuevo periodismo (1936-1939)
}

\author{
María GómeZ y PATiÑo \\ Universidad Zaragoza \\ mariagp@unizar.es
}

Recibido: 7 de marzo de 2015

Aceptado: 18 de junio de 2015

\begin{abstract}
Resumen
Este trabajo presenta y analiza la primera crónica periodístico-literaria escrita y publicada por Miguel Hernández: "Defensa de Madrid. Madrid y las ciudades de Retaguardia" durante la Guerra Civil española (1936-1939), quien inicia con ella una serie de crónicas bélicas que establece un género particular de periodismo: la crónica literaria -poético-política-. Miguel Hernández publica en diferentes periódicos del frente como cronista, con su nombre propio y con seudónimo, desempeñando también tareas de director y comisario político. Temáticamente, esta primera crónica muestra su compromiso, su deseo e incluso su estrategia para poder proteger a la capital de España. Metodológicamente, se aborda desde el giro lingüístico en Ciencias Sociales que permite explicar algunas de las peculiaridades del estilo personal del cronista Miguel Hernández. Todo ello pone de manifiesto que el llamado Nuevo Periodismo (narrativo y literario) que florece en la década de los 70 , hoy así acuñado, ya había sido practicado profusa y eficientemente por Miguel Hernández 40 años antes. Por ello, Miguel Hernández merece ser no sólo incorporado al colectivo de los grandes periodistas-cronistas junto con otros ya rescatados hasta el momento. Su estilo y calidad literaria le sitúan por tanto en una posición destacada y pionero del género actualmente conocido como Nuevo Periodismo, que es, además, políticamente comprometido.
\end{abstract}

Palabras clave: crónica de guerra; nuevo periodismo; compromiso; Guerra Civil española

\section{The first chronicle of Miguel Hernandez: The New Journalism (1936-1939)}

\begin{abstract}
This paper presents and analyzes the first literary-journalistic chronicle writen and published by Miguel Hernández: "Defensa de Madrid. Madrid y las ciudades de Retaguardia", during the Spanish Civil War (1936-1939). This chronicle is the first one of a series establishing a new and personal type of journalism: literary chronicles - poetical and political-. Miguel Hernandez published his masterpieces in different newspapers as a war reporter, with his own name and with a pen-name, playing roles of director and political commissar in different newspapers in the war-trenches. Thematically, this first article shows his personal and political engagement, as well as his desire and strategy to protect the capital city of Spain: Madrid. Methodologically, the analysis is an approached to linguistics in social sciences, which presents some of the personal characteristics and style of the chronist Miguel Hernández. Thus, it becomes patent that the so-called New Journalism (narrative and literary), which flourished in the 70s, had already been deeply and efficiently practiced by Miguel Hernández 40 years before. That is the reason why Miguel Hernández deserves to be added to the well-known collective of chronicle writers that have already been rescued to this moment. His literary style and quality are installing him in a outstanding position as well as pioneer of the genre nowadays known as New Journalism that in his case, it is politically engaged
\end{abstract}

Key words: war chronicle; new journalism; engagement; Spanish Civil War 


\section{Referencia normalizada:}

Gómez y Patiño, M. (2015). La primera crónica de Miguel Hernández: el nuevo periodismo (19361939). Historia y Comunicación Social. Vol 20, número 1, páginas 159-172.

Sumario: 1. La crónica hernandiana y su contexto. 2. Objetivos e hipótesis. 3. La relevancia del "yo": de su corazón a sus crónicas. 4. La implicación y el compromiso ideológico. 5. De la realidad y de sus figuras literarias de ficción. Su compromiso ideológico. 6. De la intertextualidad, de la coherencia y de la integración. 7. Algunas conclusiones necesarias. 8. Referencias bibliográficas.

\section{La crónica hernandiana y su contexto}

La literatura existente en torno al tema de la crónica no permite alcanzar un consenso sobre la definición de la crónica periodística. De hecho, hay tantos tipos de crónicas como cronistas, y por tanto, su determinación absoluta resulta inabordable. Está en "debate", como apunta Jorge Carrión en el prólogo a su antología Mejor que ficción (2012). No deja de ser paradójico que el término Literary Journalism (Periodismo literario) se asocie como inevitable a la crónica, al tiempo que da cabida a un sinfín de fórmulas, estilos y características que resultan difícilmente encasillables. A medida que se contemplan las posibilidades, la variedad de estilos, de miradas, de voces en la crónica, más complejo es cerrar el objetivo, encontrar un sentido unívoco de este género periodístico.

José Ismael Gutiérrez (1996:83) opina que a la crónica se ha valorado en tanto que género, ya "que refleja la problemática moderna de la temporalidad con la narrativización de los sucesos del acontecer cotidiano". Rescatar esta idea, por encima de otras, es imprescindible para esta crónica de guerra de Miguel Hernández, dado que "lo cotidiano" se convierte en "lo excepcional" por tratarse de una guerra y, al mismo tiempo se transforma en narración apasionada, lo cual es afortunadamente inevitable en su caso, pues está dando noticia de hechos bélicos, tamizados por la pasión y el estilo hernandiano. Con sus crónicas aparece un estilo propio, que utilizando algunas de las características de un periodismo referencial, hace una descripción filtrada de la realidad.

Dado que hasta ahora, han sido reconocidos como grandes cronistas, nombres citados por Chillón (1999), como Charles Dickens, Daniel Defoe, Thomas de Quincey, Truman Capote, John Hersey, Gay Talese, Tom Wolfe, Ernest Hemingway, John Dos Passos, Josep Pla, James, Mariano José de Larra, Agee y Lillian Ross, Gabriel García Márquez, Ryszard Kapuscinski, Oriana Fallaci, Eduardo Haro Tecglen, Manuel Vázquez Montalbán, Maruja Torres o Manuel Vicent, Joseph Mitchell y Rodolfo Walsh, u otros, entre los que cita Wolfe (1976): Bellow, Barth, Updike, o el mejor del lote en su opinión, Philip Roth. Por tanto, más que conveniente parece necesario analizar la obra cronística e incorporar el nombre de Miguel Hernández.

Su quehacer periodístico fue intenso, siendo el periodo más fértil en torno al año 1937. De esta etapa se conservan 32 crónicas publicadas en distintos periódicos del frente, a saber: en Al Ataque: 6; Milicia Popular: 1; Ayuda: 1; La Voz del Comba- 
tiente: 1 ; Acero: 1 ; Frente Sur: 14; Nuestra Bandera: 5; Avanzadilla: 1 y Pasaremos ${ }^{1}$ : 1.

Sus crónicas aúnan algunas circunstancias que las convierten en extraordinarias, siendo las más destacadas: 1) La universalidad de Miguel Hernández como poeta, que coloca estos escritos en un lugar determinado; 2) El compromiso ideológico republicano declarado del poeta, que ejercía como comisario político comunista. Otros cronistas bélicos como Julio Camba (quien fuera corresponsal de diversos periódicos: ABC, El Sol, La Tribuna, etc., en las guerras europeas del siglo XX) o Ryszard Kapuscinski (que por medio de su obra Un día más con vida, describió el proceso de descolonización portugués y la guerra civil de Angola desde 1975, simultaneando periodismo y literatura) que no se pronunciaron jamás de un modo tan significado por parte de ningún bando; y 3) La lucha armada. Además de con la palabra. Miguel Hernández fue combatiente en el frente y desde allí escribía. Asunto que no siempre se da en el reporterismo de guerra, que suele producir textos desde la retaguardia o como mucho en las capitanías generales de los respectivos ejércitos, como en el caso de Julio Camba y sus crónicas para $A B C$ de Sevilla. Miguel Hernández, en cambio, fue testigo y actor en el escenario bélico y no relator ausente. Nuestro cronista cumple varias funciones o misiones a un tiempo: poeta-reportero-combatiente-comisario político, hecho que quizá pueda restarle imparcialidad, pero en cambio confiere un particular rasgo de sinceridad y de congruencia a su discurso. Miguel Hernández, además de cronista de guerra, "reivindicaba -según Esteve (1993:322)- una honestidad mayor en la prensa". Ahí radica su doble compromiso en lo político-personal y en lo profesional.

\section{Objetivos e hipótesis}

A la hora de establecer los objetivos, éstos se vislumbran desde dos vertientes: el de este trabajo es posicionar a un escritor universal, conocido por su poesía, dentro del marco de la crónica y por tanto visibilizar su función como cronista bélico, dentro de la corriente que más tarde se conocería como Nuevo Periodismo. Por otra parte, para Miguel Hernández, su objetivo estaba centrado en lograr, tal como indica el título de su primera crónica aquí analizada; La Defensa de Madrid...

La hipótesis de partida se presenta claramente: la crónica hernandiana aquí presentada y analizada, que además es la primera que publica en los periódicos del frente republicano, consiste en establecer que él escribe una crónica hernandiana, que cumple todos los requisitos de la crónica característica del llamado Nuevo Periodismo.

El contexto histórico viene definido por la Guerra Civil española, que constituye un hito histórico que ha marcado la vida de los españoles. El propio enfrentamiento civil se reflejó en un vocabulario polarizado, que en el análisis aparece como: buenos/ malos, héroes/villanos; valientes/cobardes; rojos/azules, etc. Esta guerra obligó a los 
españoles a tomar decisiones políticas y a comprometerse. Miguel Hernández lo hizo. Sobre todo fue un intelectual comprometido con la ideología de la izquierda, que fue coherente y se mantuvo fiel a la Segunda República, luchando por sus valores, ideas e ideales y defendiendo la legalidad democrática conseguida en 1931. Durante la contienda llegó a actuar como comisario político del Partido Comunista, al tiempo que de cronista y director de periódicos. No fue la guerra lo que despertó su vocación periodística. Miguel Hernández ya había mostrado con anterioridad su interés por el periodismo. Prueba de ello es la carta que escribe el 10 de octubre de 1932 a Luis Almarcha Hernández (el clérigo oriolano que ejerció un gran poder político, religioso y mediático, que dirigió El Debate, El Pueblo y la revista La Lectura Popular y que llegaría a ser Obispo de León y Procurador en Cortes, por los sindicatos franquistas. Al ser oriolano como Miguel Hernández, aunque de signo distinto, tuvieron alguna relación a lo largo de su vida y no siempre afortunada). El fragmento extraído es:

He leído en el Debate del sábado 8 la convocatoria que hace dicho periódico a los aspirantes a periodistas, así como los planes de estudio en su Escuela de periodismo. Recuerdo que a mi primera, como la segunda, desdichada vuelta de Madrid me habló usted de la tal "Escuela de Periodismo"... ¿Quiere usted que vaya a visitarle en su casa esta noche, entre ocho u ocho y media, y me dice usted lo que sepa de esto? ¿Hará usted, querido don Luis, hará usted que puede por lograr una beca para mí, que no quiero "trabajar? (Sánchez Vidal, et al., 1992:2302-3).

Este poeta-cronista hubiera estudiado Periodismo y trabajado como periodista profesional si le hubieran dejado. Pero fue la guerra civil y no Almarcha quien le ofreció esta oportunidad periodística, y allí demostró que su arma preferida fue siempre la palabra, hecha poesía, teatro o crónicas de guerra. Este periodo contó con periódicos en ambos bandos que se pusieron al servicio partidista de cada causa. No hay duda de que, como explica Rubio Cremades (1993:195), los juicios y opiniones de Miguel Hernández "se vierten y se proyectan desde las páginas de una prensa puesta al servicio de la causa ideológica". Las rutinas productivas en aquellos momentos, se encontraban muy condicionadas por el desarrollo de la contienda. Y las palabras de Luis García Montero (2009:6) sirven para concretar un poco más: "Los artículos de Miguel Hernández recogen la moral comunista heroica de resistencia ante el ejército franquista". Pero no se conformó Miguel Hernández con escribir crónicas en la prensa escrita del Frente republicano. También participó en medios radiofónicos, en el Altavoz del Frente ${ }^{2}$ o en lo que se denominaba "Batallón del Talento", en el que se recitaban poemas para generar una atmósfera poético-literaria entre los soldados. De este modo, el poeta oriolano asumía una parte de la formación política y cultural de los milicianos.

De su experiencia como cronista en la guerra, Miguel Hernández también extrajo algunas lecciones para el periodismo, que reproduce Francisco Esteve (2009: 12): "La prensa no sería tantas veces irritante o aburrida si algunos de los que escriben sus diarios se acercaran más oportuna y menos prudentemente a los campos donde la verdad habla a balazos". En síntesis, Miguel Hernández: 1) escribía lo que vivía, siendo testigo presencial; y 2) era un ejercicio de honestidad y coherencia, lo que le valió la pena de muerte. 
A esta implicación que singulariza la labor del cronista Miguel Hernández hay que añadir otra circunstancia diferenciadora: nunca abandonó España. Otros reporteros bélicos destacables de la Guerra Civil española como Manuel Chaves Nogales o Arturo Barea partieron hacia el exilio, pero Miguel Hernández se quedó, lo que dio lugar a su juicio, condena y muerte. No es difícil imaginar que no es lo mismo escribir una crónica bélica desde otro país que hacerlo desde el frente de batalla. Pasó de ser un cronista comprometido y destacado a convertirse en un héroe, como otros tantos seres anónimos que murieron víctimas de la guerra.

Si bien la figura de Miguel Hernández ha sido estudiada especialmente como poeta, no faltan estudios, incluso de relevantes hispanistas y hernandistas que se han adentrado en la obra periodística de Miguel Hernández. Se puede afirmar que, a pesar de que la obra periodística-poética-política no ha merecido el mismo espacio para los estudios críticos de la obra poética, Juan Cano Ballesta (1993:136) opina de los artículos de prensa hernandianos que son:

páginas escritas a un ritmo febril y precipitado, entre las incomodidades y sobresaltos del frente, que le impiden prestar demasiada atención a valores formales y artísticos. En ellas literatura e ideales humanos, arte y vida cristalizan en un lenguaje intenso y apasionado que le compromete radicalmente.

La figura de Miguel Hernández ha sido estudiada fundamentalmente como poeta. Sin embargo no faltan estudios relevantes de hispanistas y hernandistas sobre su obra periodística. Juan Cano Ballesta (1978) considera que ésta puede dividirse en cuatro grandes bloques: 1) Artículos de arenga política; 2) crónica y narración épica; 3 ) artículo informativo y de orientación; y 4) meditación teórica sobre el arte de la guerra.

La primera crónica hernandiana, publicada en Al Ataque, $n^{\circ} 2$, -16-01-1937, es el centro de este trabajo:

"Defensa de Madrid. Madrid y las ciudades de Retaguardia"

Con el personal estilo hernandiano, esta crónica, participa de todos los géneros citados. Por ello, podría decirse que su obra periodística constituye un corpus cronístico de diferente naturaleza: 1) crónicas políticas; 2) narrativas; 3) instructivas; y 4) reflexivas, según la naturaleza y el contenido de sus escritos. En todas ellas, no obstante, es crucial la mirada y estilo literario del poeta-periodista, (cronista) que escribe en primera persona, desde su "yo".

\section{La relevancia del "yo": de su corazón a sus crónicas}

Uno de los rasgos más característicos de esta clasificación es el origen de la mirada del cronista: habla desde su corazón, desde sus sentimientos, desde su yo. Es un periodismo personal y subjetivo. Lo expresa muy bien Blasco (1977:47): "El tema -cualquier tema- debe primero hacerse carne con él". Esta característica lo relaciona con algunos cronistas contemporáneos que reivindican el uso de la primera persona, 
como Darío Jaramillo (2012:22-23), que hace una defensa de la personalización del cronista:

Nos convencieron de que la primera persona es un modo de aminorar lo que se escribe, de quitarle autoridad. Y es lo contrario frente al truco de la prosa informativa (que pretende que no hay nadie contando, que lo que cuenta es "la verdad"), la primera persona se hace cargo, dice esto es lo que yo ví, yo supe, yo pensé (...) siempre hay un sujeto que mira y que cuenta. Que hace literatura.

Miguel Hernández, además del yo, utiliza el nosotros. Una primera persona plural absolutamente incluyente, con la que involucra al colectivo del que forma parte y se siente cómodo, haciendo que ellos se sientan orgullosos de la pertenencia a ese colectivo.

En la crónica "Defensa de Madrid. Madrid y las ciudades de retaguardia", el propio título recuerda el eslogan difundido por la prensa oficial y extraoficial "Defensa de Madrid", con un marcado carácter vocativo e imperativo de movilización. Otros autores, como Manuel Chaves, tienen otra crónica titulada "Defensa de Madrid". Con este título también se realizó un documental.

Metodológicamente, el análisis se fundamenta sobre todo en la literatura primaria. En este caso, la crónica seleccionada para ser analizada es Defensa de Madrid. Madrid y las ciudades de Retaguardia que constituye el material de análisis que, junto con la literatura secundaria procedente de hernandistas internacionalmente reconocidos, permiten reconstruir el contexto histórico, social y político que le tocó vivir a Miguel Hernández en el frente republicano. Por tanto, el texto ha sido analizado, desde el texto/mensaje, en base a distintas disciplinas, como el Análisis del Discurso (Abril, 1994; Bardin, 198; Barthes, 1993; Chatman, 1990; Cicourel, 1982; Greimas, 1980; Ibáñez, 1985; Jakobson, 1983; Maingueneau, 1976; Reis, 1982); Análisis de Contenido (Krippendorff, 1990); y lo que en Sociología se conoce como el giro lingüístico, que permite analizar, desde una base literaria o textual, cuestiones tanto de contextualización sociológica como psicológica.

Como rasgo característico, Miguel Hernández emplea en este texto la primera persona, haciendo crónica de su situación: “...cuando estos hombres, digo, están viviendo en las trincheras unos días inacabables de hambre, fuego y muerte..." ("veo", "siento") y expresa abiertamente su estado de ánimo ("pesadumbre y cólera"). La peculiaridad de la primera persona en sus crónicas es la emotividad en sus palabras. Es una expresión de los sentimientos que se relaciona con el uso de apelaciones emocionales, singularmente eficaces como técnicas generales de persuasión (Roiz, 1994) que se adapta perfectamente a los destinatarios de sus crónicas, miembros del bando republicano en el frente. De hecho, afirma: "No puede ser. Hemos de acabar con este disfrazado fascismo". Mientras que en la primera persona del singular, el cronista describe; en la primera persona del plural: el cronista se involucra de forma incluyente (nosotros elidido).

María Isabel Cintas (2011:21) explica que Manuel Chaves Nogales trataba de conseguir la objetividad, de ahí su "búsqueda de la imparcialidad". En cambio, 
Miguel Hernández no pretendía ser imparcial. Al contrario, mostró abiertamente su compromiso con el frente republicano donde se encontraba. Fue un periodista apasionado porque sus crónicas son las de un poeta en la guerra que conmueve con su palabra a todos los combatientes del frente. La objetividad nunca fue una de sus preocupaciones. Su narrativa nunca buscó una descripción aséptica de la realidad del frente. Más bien al contrario, se dejaba llevar por sus emociones que impregnaban todos sus actos. "Hernández era un "significador" (Gómez y Patiño, 1999:294) cuya realidad social se crea por sus actos de significaciones y los de los otros miembros de su entorno, en términos de cohesión, o del sentido último de la lucha". Su estilo literario está impregnado de una alta emotividad que se deja sentir tanto en sentido positivo como negativo. Esta expresión de los sentimientos está relacionada con la utilización de las apelaciones emocionales, singularmente eficaces como técnicas generales de persuasión (Roiz, 1994).

\section{Realidad y figuras literarias de ficción: Su compromiso ideológico}

Desde el análisis del discurso sociolingüístico mencionado, es muy profusa la utilización de figuras literarias por parte de Hernández. No en vano el poeta metido a cronista no abandona nunca su lenguaje, su simbología y sus figuras discursivas y literarias. En este sentido, Juan Cano Ballesta (1993:136) recuerda que los artículos de prensa hernandianos son:

páginas escritas a un ritmo febril y precipitado, entre las incomodidades y sobresaltos del frente, que le impiden prestar demasiada atención a valores formales y artísticos. En ellas, literatura e ideales humanos, arte y vida, cristalizan en un lenguaje intenso y apasionado que le compromete radicalmente.

Las crónicas de Hernández constituyen textos de urgencia escritos bajo la presión de los acontecimientos bélicos. Sin embargo, el cronista-poeta utiliza algunas figuras que remiten al lector a sus textos poéticos. En "Defensa de Madrid. Madrid y las ciudades de retaguardia", Miguel Hernández acude a la personificación, y se refiere a la ciudad como una mujer "desnuda, muda y serena", y también como una persona "desesperadamente deseada" y "firmemente defendida", sentimientos fáciles de asumir para cualquier hombre-soldado-combatiente-lector. Otra expresiva personificación es: "Madrid se conmueve y se desangra".

En esa misma crónica, el propio Miguel Hernández se incluye en la clase social "campesina", a la que define en sus atributos con el uso de términos líquidos, naturales y agrarios: "barro", "sangre" y "lluvia". Y no es la única metáfora agraria del texto, pues también espera que las muertes "no sean siembra en páramo baldío". Es más, se refiere a las muertes con una perífrasis poetizada: "vidas derramadas".

Siguiendo en esta misma crónica, pueden encontrarse metáforas de tipo cromático, como "salpicando de luto el corazón", y de orden espiritual y "depuración y desinfección de las ciudades", todo lo cual además de tener un alto grado de narración 
cronificada, apela a metáforas altamente poetizadas, que ratifican el posicionamiento ideológico del cronista.

Haber traído a colación la primera crónica periodística de la cronicología hernandiana permite una comparación con otros cronistas de guerras, como Julio Camba o Ryszard Kapuscinski, dos ejemplos representativos, que jamás se comprometieron de tanto como lo hizo Miguel Hernández, quien utiliza técnicas persuasivas e incluso fuerza algunas oposiciones: "buenos" y "malos" o "héroes" y "villanos", para mostrar inequívocamente el enfrentamiento bélico y su posición junto a los "buenos". Concretamente, si se aplica la terminología propuesta por Vladimir Propp (1985) a su crónica "Defensa de Madrid. Madrid y las ciudades de retaguardia", se observa que los "héroes" son hombres del pueblo, campesinos, obreros, juventud, madres y compañeros, mientras que los "villanos" son italianos y alemanes, enemigos, verdugos, carteleros, fascismo, señoritos, histriones, revolucionarios de relumbrón, héroes de opereta. La polaridad proppiana "héroes-villanos" tan patente en las crónicas de Miguel Hernández está justificada por el hecho de tratarse de un enfrentamiento bélico, que impide una neutralidad natural. La confrontación es por tanto, bélica y lingüística. Por otra parte, la utilización de un vocabulario relacionado con el mundo del teatro: "histriones", "héroes de opereta", "carne de carnaval", evoca un sentido de farsa que debe ser compensado con un esfuerzo por "ennoblecer" y "dignificar" a los hombres de retaguardia.

En esta misma crónica, Miguel Hernández subraya el contraste entre Madrid y las ciudades en la retaguardia. En el primer caso, sus palabras son muy emotivas y laudatorias. En el segundo, el lenguaje se endurece hasta convertirlo en recriminatorio para quienes se encuentran en la retaguardia: "señoritos que no podían serlo, y lo son en cuanto pueden", "los traidores extranjerizantes", y "los enemigos de España". La crónica bélica se desarrolla en el escenario del frente. No puede olvidarse lo que Kapuscinski (2007) dijera en su plena madurez, poco antes de su muerte: que otra fuente para el periodismo son las personas que uno encuentra en el camino.

El hecho de escribir sus crónicas desde los frentes de batalla, unido a las características propias de su estilo, permite afirmar que está creando un paradigma de crónica, en el sentido en que Kuhn (2012) lo ha venido utilizando, que no sólo permite ser analizado, sino emulado.

Fue un cronista en el sentido más exacto del término, dado que hacía crónica de su paso por los frentes. La contemplación de la ciudad de Madrid, a lo largo de la "Batalla de Madrid"- Recuérdese que Miguel Hernández vivió esta batalla. Pasó por la ciudad universitaria, Boadilla del Monte y Brunete, lo que le ofreció la posibilidad de describir lo que él ve y siente, una crónica subjetiva y personal, que hace crónica desde un posicionamiento bélico inequívoco. Nuestro cronista ya fue un periodista multitarea (multitask) pues cumplía varias funciones o misiones simutáneas: cronista, poeta, combatiente, comisario político, director de periódico, locutor en el Altavoz del Frente, e incluso educomunicador (Gómez y Patiño, 2013), hecho que aun pudiendo restarle imparcialidad, le confiere un particular rasgo de integridad 
a su discurso. Un buen ejemplo lo constituye su reflexión sobre la mejor actitud del combatiente para conservar su salud física y mental. Miguel Hernández produce diversos géneros literarios con el mismo tema, en los que se aprecia inequívocamente la intertextualidad que le caracteriza.

\section{De la intertextualidad, de la coherencia y de la integración}

Miguel Hernández hizo de sus crónicas de urgencia una extensión, o mejor una correspondencia, del resto de su obra. Tanto su producción periodística-las crónicascomo la literaria -poesía, teatro, epistolario personal- están íntimamente relacionadas. La intertextualidad es un rasgo sobresaliente, que elaborado en el ambiente del estructuralismo francés de los años 60 se inscribe en una perspectiva multidireccional y vanguardista, sobre esta semiótica-objeto proteiforme que es el texto, definido en términos de proceso y de producción (Greimás/Courtes, 1991).

Los temas que le preocuparon se extienden por toda su producción. El tema tratado en "Defensa de Madrid. Madrid y las ciudades de retaguardia", también aparece en su producción teatral, con su obra dramática Los sentados, en la que denuncia la indiferencia de las ciudades de la retaguardia: "Mientras que los que tenemos el alma en pie defendemos el pan y la España que codician italianos y alemanes, vosotros seguíais haciendo vuestra cómoda vida de gallinas en el nido" (Sánchez Vidal et al. 1992. Vol. II:1811).

En poesía retoma el compromiso y la muerte durante la Guerra Civil española. De hecho, existe una relación textual entre algunas palabras de su crónica "Defensa de Madrid. Madrid y las ciudades de retaguardia" ("apretar los dientes y el alma") y lastre con su epistolario personal (Cartas a Josefina), donde va dando cuenta a su pareja de los episodios de la guerra, de una forma intimista y humanizada, con el fin de generar un menor impacto en Josefina (su mujer desde la primavera de 1937): "Échale la culpa a los fascistas que no nos dejan poner la paz sobre España". (Sánchez Vidal et al., 1992. Vol. II: 2485).

En Miguel Hernández se cumple la máxima de la integridad personal consistente en "hacer de su vida su obra y de su obra su vida". No existe límite entre ellas dos. Vida y obra se integran en un todo que, finalmente, entreteje y construye la intertextualidad anteriormente aludida. Esta circunstancia no se produce exclusivamente por las alusiones a episodios familiares o personales o por las referencias veladas a su Orihuela natal, sobre las que llama la atención Enrique Rubio Cremades (1993:194), sino también, como afirma el mismo estudioso, porque muchas de sus páginas en prosa "describen el comportamiento ejemplar de sus mandos o, simplemente de milicianos anónimos que han dado su vida en la contienda por la lucha de un ideal". La dignidad viene asociada con ganar la guerra, que es la única forma de vivir con dignidad. De no conseguir la victoria, la mirada hernandiana propone lograr la inmortalidad en el pueblo al poseer un héroe producido por la derrota, idea presente también 
en su poesía. Miguel Hernández parecía anticiparse a su propio final y al de tantos otros héroes anónimos.

Valorar su obra se torna en una tarea fácil si se compara con otros cronistas que reflejaron conflictos bélicos, y cuya vida nunca se vio tan comprometida Miguel Hernández, a diferencia de otros cronistas, nunca abandonó España. Mientras otros lo hicieron, Miguel Hernández se quedó, lo que dio lugar a la condena y a su muerte: se inmoló. Hecho éste que le ha convertido en héroe, además de cronista. Estas razones son tan poderosas que la gestión social de su discurso periodístico (Salvador, 2002) es necesariamente muy diferente de la de otros cronistas.

Cada "historia contiene además otra historia, y ésta otra a su vez, y así sucesivamente, hasta producir el efecto de una colección de muñecas rusas, que sin saber cuántas contiene se siguen abriendo sin respiración hasta llegar a la última, al final" (Gómez y Patiño, 1994:2). Para conseguir este efecto Miguel Hernández se va sirviendo de las distintas funciones del lenguaje. Utiliza la función expresiva mediante la manifestación constante de sus ideas, sentimientos y emociones: "pesadumbre y cólera". Conseguido este efecto pasa a otro plano con la función conativa: repite el verbo "decir" en primera persona de singular, con una intención apelativa de movilización. Una vez logrado su propósito, utiliza una función referencial: ofreciendo información sobre el fascismo en Europa, al que hay que combatir, para concluir con una función poética, con la utilización de expresiones poetizadas: "el pueblo madrileño sacudido y despedazado", que consigue el clímax necesario en esa sucesión de muñecas rusas persuasivas, o si se prefiere, yendo de una función a la otra sin solución de continuidad. De hecho, Miguel Hernández nunca tuvo intención de ser un analista político aunque su mirada diera en la diana en tantas ocasiones. Con sus crónicas conseguía una clara movilización emocional, lo que viene a su vez apuntalado por la aportación de George Sampson (2005) sobre el lenguaje instintivo, el que aparece como resultado de los propios sentimientos o instintos. En este sentido, hay que recordar que Miguel Hernández ha sido de los poetas universales más instintivos. En mi opinión, la crónica hernandiana tiene algo de lo que George Cantor (1989) definió como una retórica del experimento. Experimento, en este caso, en el sentido de probar "algo", unas diferencias literarias que formaban parte de su estilo y que no se había experimentado hasta ese momento.

\section{Algunas conclusiones necesarias}

Este análisis permite afirmar que Miguel Hernández hizo de sus crónicas de urgencia una extensión del resto de su obra. Su producción periodística y la literaria están íntimamente relacionadas, siendo la intertextualidad un rasgo característico e inequívoco de su obra. Los temas que le preocuparon transitan por toda su obra. Su mirada y su voz comprometida se ponen de manifiesto en toda su producción. Así, en teatro (Teatro en la Guerra), re-elabora el tema de la "Defensa de Madrid. Madrid y las 
ciudades de Retaguardia", con su obra dramática "Los sentados", en la que denuncia la indiferencia de las ciudades de la retaguardia; en poesía "Vientos del pueblo me llevan", retoma el compromiso y la muerte durante la Guerra Civil, cuyo texto ha sido cantado por un buen número de canta-autores hispanos, con versos como "/ vais de la vida a la muerte /, / vais de la nada a la nada/": o en su epistolario personal (Cartas a Josefina). En estas cartas va dando cuenta a su novia primero (se casa con Josefina Manresa el 9 de marzo de 1937), y a su esposa después, de los episodios de la guerra, narrados en poesía, teatro o crónicas periodísticas.

En Miguel Hernández se cumple una constante de integridad consistente en hacer de su vida su obra y de su obra su vida. Ambas se integran en un "todo único" que entreteje y construye la intertextualidad analizada, al tiempo que construye su vida.

Muchos estudiosos de la obra hernandiana han vislumbrado esta interconexión, como por ejemplo, Enrique Rubio Cremades (1993:194), quien observa:

En su conjunto las prosas de guerra actúan como un canal transmisor de aquellos hechos heroicos realizados por sus compañeros de milicia. Páginas (...) que describen el comportamiento ejemplar de sus mandos o, simplemente de milicianos anónimos que han dado su vida en la contienda por la lucha de un ideal. No faltan en estas prosas las alusiones a episodios familiares o personales ni las referencias veladas a su Orihuela natal.

La crónica analizada conforma un periodismo personal y subjetivo, sin perder un ápice de su autenticidad y veracidad. Él crea su propio paradigma (Kuhn, 2012) narrando lo que ve y lo que siente, como un cronista oficial. Nunca son historias planas y lineales, se presentan continuas y superpuestas, como una sucesión de personas con las que el viajero se va encontrando en su camino (Kapuscinski, 2007). No puede olvidarse que la figura de Miguel Hernández es poliédrica en tanto que comunicador político, cronista de guerra y comisario político pero muy especialmente poeta, aspecto que hay que recordar, dado que la significación y poética que envuelve su producción periodística es evidente. Un filtro literario y poético que se suma a su compromiso personal, social y político con la causa republicana que convierten en un producto único sus crónicas: las crónicas hernandianas, que no dejan de ser las de un poeta en tiempos de guerra que conmueve con su palabra a los combatientes del frente. Sus textos políticos, poetizados e ideologizados transcienden al periodismo informativo al uso para convertirse en un "periodismo literario", en "crónicas literarias", donde se cumplen todas las funciones del lenguaje.

En síntesis puede decirse que Miguel Hernández fue un cronista apasionado, instintivo (Sampson, 2005) y comprometido, que mediante su intertextualidad se sitúa claramente en un periodismo literario, personal y único, cuya obra periodística, o cronística, pone de manifiesto que él ya practicó en 1937, como una contribución retórica experimental (Cantor, 1989), lo que cuarenta años después se conocería como Nuevo Periodismo, crónicas literario-narrativas, o la nueva narrativa periodística. A los cronistas literarios ya reconocidos, ha de sumarse el nombre de Miguel Hernández. 


\section{Referencias bibliográficas}

ÁLVAREZ, J. T. (1989). Historia de los medios de comunicación en España: periodismo, imagen y publicidad, 1900-1990. Barcelona: Ariel.

BARDIN, L. (1986). Análisis de contenido, Madrid: Akal. Publicado en francés por Presses Universitaires de France (1977), y traducido por César Suárez.

BARTHES, R. (1993). La aventura semiológica, Barcelona: Paidós.

BLASCO, R. (1977).“Miguel Hernández, corresponsal de guerra”. Nueva Historia. Abril. Núm. 3, pág. 39-50, y Mayo. Núm. 4, pág. 64-81.

CANO BALLESTA, J. (1978). "Miguel Hernández: poeta comprometido, periodista y narrador épico". En torno a Miguel Hernández. Madrid: Castalia.

CANO BALLESTA, J. (1992). "Una prosa desconocida" de Miguel Hernández". En DÍEZ DE REVENGA, F. J y DE PACO, M. Estudios sobre Miguel Hernández. Murcia: Universidad de Murcia, pág. 47-62.

CANTOR G. (1989). "The Rhetoric of experiment", en GOODING, P; PINCH, T \& SCHAFFER, S. (Eds.). Uses of experiment. Cambridge: Cambridge University Press. Pág. 159-180.

CHAVES NOGALES, M. (2011). La defensa de Madrid. Sevilla: Espuela de Plata.

CHILLÓN, A. (1999). Literatura y tradición de relaciones promiscuas. Universitat Autònoma de Barcelona; Universitat Jaume I; Universitat de València.

CICOUREL, A.V. (1982). El método y la medida en sociología, Madrid: Editora Nacional.

CINTAS GUILLÉN, M. I. (2011). "Notas a la edición”, en CHAVES NOGALES, M. La defensa de Madrid. Sevilla: Espuela de Plata. Pág. 3-22.

DÍEZ DE REVENGA, F. J y DE PACO, M. (1992). Estudios sobre Miguel Hernández. Murcia: Universidad de Murcia.

ESTEVE, F. (1993). "Miguel Hernández, periodista”, en Rovira, J.C., (Ed.) Miguel Hernández, 50 años después. Actas del Congreso Int. Miguel Hernández, Vol I y II. Alicante: Comisión del Homenaje a Miguel Hernández. Vol. I, pág. 319-324.

ESTEVE, F. (2009). "Miguel Hernández. Un periodista comprometido". En Miguel Hernández. Crónicas de la guerra civil. Un poeta en el frente, Madrid: Sol90. Pág. 9-21.

GARCÍA MONTERO, L. (2009). "Tristes guerras” en Miguel Hernández. Crónicas de la guerra civil. Un poeta en el frente, Madrid: Sol90.

GÓMEZ y PATIÑO, M. (1994). "Miguel Hernández, cronista", Sup. Arte y Letras, Información, Alicante, 29 de diciembre. Pág. 2-3.

GÓMEZ y PATIÑO, M. (1997). "Miguel Hernández y el $1^{\circ}$ de mayo en la Guerra Civil española (1936-1939)", Cuadernos Republicanos, Madrid, Junio. N 31, 39-44.

GÓMEZ y PATIÑO, M. 1999): Propaganda poética en Miguel Hernández. Un análisis de su discurso periodístico y político, Alicante: Instituto de Cultura Juan Gil-Albert.

GÓMEZ y PATIÑO, M. (2012). "La función social del periodismo en tiempos de Guerra: el caso de Miguel Hernández”, en Miguel Hernández / 1910-2010. III 
Congreso Internacional, Vol. I. y II. 804 páginas. (Vol. I, pág. 305-315). Alicante: Instituto Alicantino de Cultura Juan Gil-Albert.

GÓMEZ y PATIÑO, M. (2013). "Comunicación Política y Educación en tiempos de guerra: El caso de Miguel Hernández", Index Comunicación. Num. 3, pág. 121-137, Madrid: Universidad Rey Juan Carlos.

http://journals.sfu.ca/indexcomunicacion/index.php/indexcomunicacion/article/ view/52.

GOODING, P; PINCH, T \& SCHAFFER, S. (eds.) (1989). Uses of experiment. Cambridge: Cambridge University Press.

GREIMAS, A.J. (1980). Semiótica y Ciencias Sociales, Madrid: Fragua.

GREIMAS, A.J. \& COURTES, J. (1991). Semiótica. Madrid: Gredos.

GUERRERO ZAMORA, J. (1990). Proceso a Miguel Hernández: El Sumario 21.001. Madrid: Dossat.

GUILLÉN, N. (1943). "Milicia y permanencia de Miguel Hernández". En Homenaje a Miguel Hernández. La Habana: Palacio Municipal de La Habana. Pág. 9-14.

GUTIÉRREZ, M. I. (1996). Manuel Gutiérrez Nájera y sus cuentos. Nueva York: Peter Lang.

HERRSCHER, R. (2012): El Periodismo narrativo. Barcelona: Universidad de Barcelona.

IBAÑEZ, J. (1985). “Análisis sociológicos de textos o discursos", Rev. Int. Sociología, Madrid, (43) 119-160.

JAKOBSON, R. (1983): Lingüistica y Poética, Madrid: Cátedra.

JARAMILLO AGUDELO, D. (Ed.) (2011). "Collage sobre la crónica latinoamericana del siglo veintiuno". En Antología de crónica latinoamericana actual, Madrid: Alfaguara Pág. 11-50.

KAPUSCINSKI, R. (2007). "El arte de reportear". El Universal. México. 24-1-2007 http://www.eluniversal.com.mx/cultura/51281.html.

KRIPPENDORFF, K. (1990): Metodología del análisis de contenido, Barcelona: Paidós.

KUHN T. S. (2012). Structure of scientific revolutions. Chicago: Chicago University Press.

LÓPEZ PAN, F. (2010). "Periodismo literario: entre la literatura constitutiva y la condicional”. Ambitos. Núm. 19, pág. 97-116.

http://grupo.us.es/grehcco/ambitos 19/06lopez.pdf.

MAINGUENEAU, D. (1980). Introducción a los métodos del análisis del discurso: problemas y perspectivas, Buenos Aires: Hachette.

MARTÍN, E. (1992). "La militancia comunista de Miguel Hernández". Ínsula. Abril, Núm. 544, pág. 5-7.

MUÑOZ MOLINA, A. (2011). "Manuel Chaves Nogales y la experiencia del derrumbe". En Chaves Nogales, M. La defensa de Madrid. Sevilla: Espuela de Plata. Pág. 7-11.

NÚÑEZ DE PRADO S. y MARTÍN DÍEZ, M. A. (1996). Estructura de la Comunicación Mundial. Madrid: Universitas.

PÉREZ ÁlVAREZ, R. (1984). “Testimonios”. Canfali Vega Baja.12-12-84. Pág. 4. 
PIZARROSO, A. (1992). De la Gaceta Nueva a Canal Plus: breve historia de los medios de comunicación en España. Madrid: Complutense.

PROPP, V. (1985). Morfología del cuento. Madrid: Fundamentos.

ROIZ, M. (1994). Técnicas modernas de persuasión. Madrid: EUDEMA.

SÁNCHEZ VIDAL, A.; ROVIRA, J.C. y ALEMANY, C. (1992). Obra Completa, I y II. Edición crítica de MIGUEL HERNÁNDEZ. Madrid: Espasa Calpe.

ROVIRA, J.C. (Ed.) (1993). Miguel Hernández, 50 años después. Actas del Congreso Int. Miguel Hernández, Vol I y II. Alicante: Comisión del Homenaje a Miguel Hernández.

RUBIO CREMADES, E. (1993). "Nuevos aspectos de la prosa hernandiana". En ROVIRA, J.C. (Ed.). Miguel Hernández, 50 años después. Actas del Congreso Int. Miguel Hernández, Vol I y II. Alicante: Comisión del Homenaje a Miguel Hernández. Pág. 191-200.

SALVADOR, V. (2002). "Discurso periodístico y gestión social de los conocimientos: algunas observaciones sobre la didacticidad”. Anàlisi. Núm. 28, pág. 107-120.

SAMPSON, G. (2005). The' language instict' debate. London: Continuum.

WOLFE, T. (1976). El nuevo periodismo. Barcelona: Anagrama.

\section{Notas}

1 En el proceso de estudio de sus crónicas tuve ocasión de trabajar con un ejemplar encuadernado en piel, a tamaño natural, de los ejemplares que Santiago Álvarez había llevado con él hasta el exilio francés. Actualmente este volumen está en el Archivo del Partido Comunista de España, Madrid.

2 El Altavoz del Frente era un camión-altavoz que, dependiendo del Ministerio de la Guerra, colaboró con la Alianza de Intelectuales Antifascistas, cuya misión era hacer llegar la propaganda político-bélica. Tenía un alcance de $2 \mathrm{~km}$. Tanto podía levantar los ánimos de los combatientes de un lado como hundir a los del contrario. Se leían poemas: Alberti, Hernández..., u otro tipo de contenido no necesariamente literario. Para obtener imágenes relativas a este artilugio propagandístico, véase fragmento del documental Tierra de España, de Joris Ivens (1937) con guión de Dos Passos y Hemingway, en $\mathrm{http}: / / \mathrm{www}$. youtube.com/watch? $=0 \mathrm{gIPDxUcaYw}$. 